Randomized Trial

\title{
Calcitonin as an Additive to Local Anesthetic and Steroid Injection Using a Modified Coronoid Approach in Trigeminal Neuralgia
}

Nabil Ali Elshiek and Yasser Mohamed Amr

From: Department of Anesthesiology, Tanta University, Faculty of medicine, Tanta, Egypt

Address Correspondence: Yasser Mohamed Amr Department of Anesthesiology

Tanta University Hospital Anesthesia Department Tanta University Tanta 31257-Egypt E-mail:

yasser.amr@gmail.com

Disclaimer: There was no external funding in the preparation of this manuscript. Conflict of interest: Each author certifies that he or she, or a member of his or her immediate

family, has no commercial association (i.e., consultancies, stock ownership, equity interest, patent/licensing arrangements, etc.) that might pose a conflict of interest in connection with the submitted manuscript.

Manuscript received: 01-06-2016 Accepted for publication: 03-16-2016

Free full manuscript: www.painphysicianjournal.com
Background: Pharmacotherapy is the main treatment for management of trigeminal neuralgia. However, many patients become refractory to drugs.

Objectives: The present study aimed to evaluate the effect of adding calcitonin to local anesthetic and methylprednisolone using a modified coronoid approach in management of trigeminal neuralgia pain involving the mandibular and/or maxillary branches.

Study Design: Randomized double blind clinical trial.

Setting: Hospital outpatient setting.

Methods: Thirty-three patients received maxillary and mandibular blocks by a modified coronoid approach. Patients were allocated into 2 groups. Group 1 received a block with $3 \mathrm{~mL}$ of lidocaine $0.5 \%$ plus $40 \mathrm{mg}$ of methylprednisolone and another syringe contained $1 \mathrm{~mL}$ of $0.9 \%$ saline. Group 2 received a block with $3 \mathrm{~mL}$ of lidocaine $0.5 \%$ plus $40 \mathrm{mg}$ of methylprednisolone and another syringe contained 50 international units of calcitonin. Pain was evaluated by visual analog scale (VAS) before the block (basal), at 2 weeks, one month after the procedure, and monthly for one year. Duration of the effective pain relief of the first block (VAS $\leq 3$ ) was reported. Repeated blockade was allowed for any patient reporting a VAS $>30 \mathrm{~mm}$ during one year of follow-up and the number of blocks were reported. Adverse effects were also reported.

Results: A significantly longer duration of effective pain relief was noticed in group 2 compared with group $1(P<0.0004)$ while the duration of effective pain relief of the second block in group 1 was $28.5 \pm 8.9$ weeks. Four patients did not need repeated blocks in group 1 versus 15 in group 2. Six patients received 2 blocks versus 2 patients in each group, respectively. Moreover, 6 patients needed 3 blocks in group1 versus none in group 2. No serious adverse events were reported during or after the interventional procedure. VAS was comparable in both groups $(P>0.05)$.

Limitations: Small sample size.

Conclusion: Calcitonin may be a useful additive to local anesthetic and steroid in management of trigeminal neuralgia. Also, a modified coronoid approach for maxillary and mandibular nerve is simple, free of radiation, safe, and may be an effective percutaneous procedure in trigeminal neuralgia.

Key words: Calcitonine, modifed, coronoid approach, trigeminal neuralgia

Pain Physician 2016; 19:457-464 
T rigeminal neuralgia is considered one of the most debilitating pain disorders (1). Many patients can be managed by carbamazepine (2), oxcarbazepine (3), or baclofen for long periods (4). Unfortunately, some become refractory to drugs $(4,5)$. There is weak evidence on the efficacy of neurodestructive procedures (percutaneous interventions of the Gasserian ganglion, stereotactic surgery, or microvascular decompression). Although they may alleviate pain to different extents, many may have sensory side effects $(6,7)$.

In order to avoid these complications, mandible and maxillary nerve blocks using a coronoid approach have been used as an alternative to minimize risks (8). However, accidental injury to the auditory tube (9), retrobulbar hematoma, persistent paresthesia, numbness, paralysis of the abducens and penetration of the nasal cavity have been reported during mandibular nerve block (10). Moreover, these maneuvers are usually painful (8). So, we have postulated that modification of the technique to stop the needle after hitting the lateral pterygoid plate without extending the needle beyond it to elicit paresthesia may be safer (11).

Particulate steroid was added to local anesthetic to achieve prolonged pain relief. However, the risks of repeated injections of steroids are well known, so the presence of the other additive added to the steroid to minimize the need for repetition of the block seems to be crucial. Calcitonin-induced analgesia might be attributed to its effects on prostaglandin and thromboxane synthesis, calcium influx, the cholinergic and serotoninergic systems, B- endorphin release, and a direct action on central nervous system receptors (12).

This study was designed to evaluate whether the addition of calcitonin to local anesthetic and methylprednisolone has a longer analgesic effect over the combination of methylprednisolone and local anesthetic using a modified coronoid approach in trigeminal neuralgia involving the mandibular and/or maxillary branches.

\section{Methods}

After the approval of the institutional ethical committee, 63 adult patients who were suffering from chronic trigeminal neuralgia for more than 6 months duration were referred to our institutional pain clinic from January 2012 to December 2013.

Exclusion criteria included patients who had infection at the site of needle entry; coagulopathy; renal, cardiac, or hepatic diseases; glaucoma; diabetes mellitus; hypocalcemia; known allergy to either steroids, local anesthetics, or calcitonin; and patients with an ophthalmic distribution of trigeminal neuralgia.

\section{Patient Evaluation and Preparation}

At the first visit to the pain clinic, after taking a medical history and a thorough clinical examination, the type of pain was evaluated. Trigeminal neuralgia had been diagnosed according to White and Sweet criteria (13): paroxysmal pain, pain that may be triggered by a light touch to the face, pain that is confined to the distribution of the trigeminal nerve, and pain that is unilateral.

Sixty-three patients were assessed for eligibility; 14 were found to be suffering from atypical facial pain and excluded. Forty-nine patients who had received oral carbamazepine up to $600 \mathrm{mg}$ in divided doses every 24 hours as the first line treatment were assessed after 2 weeks. In case of failure to achieve improvement (a $50 \%$ reduction in pain score and a decrease in attack frequency by $>50 \%$ ), carbamazepine was substituted with pregabalin 150 - $300 \mathrm{mg}$ daily. After another 2 weeks, the patients were re-evaluated to assess their improvement. Sixteen patients who reported a reduction in their pain of more than $50 \%$ and a decrease of attack frequency by $>50 \%$ were excluded from the study. So, 33 patients were recruited and randomly allocated in each group.

\section{Study Procedures}

Randomization was performed by previously prepared cards for 2 groups put in closed envelopes, indicating the group to which patients were assigned. A blinded chief nurse, who was not involved in the study or in data collection, read the number contained in the envelope and made the group assignment.

A pain specialist, blinded to the randomization, was responsible for follow-up of patients, and types and dosing of analgesic medications. A senior resident, blinded to the randomization, performed patient assessments and reported data. The interventionalist was a pain physician who performed the blocks.

An intravenous catheter (20 G) was inserted in a peripheral line for crystalloid infusion and sedation. Patients were given intravenous midazolam $0.05 \mathrm{mg} /$ $\mathrm{kg}$ before the procedure. Basic monitoring with noninvasive arterial blood pressure, electrocardiogram, and pulse oximetry was applied during the procedure. The participants were randomly assigned into 2 groups.

The patient was made to lie supine with his head resting on a pillow. The head was turned towards the 
contralateral side. The coronoid notch of the mandible was identified by asking the patient to open and close the mouth $2-3$ times. It is roughly located in front of the external auditory meatus and below the zygomatic arch. The skin was painted with povidone iodine. The area was infiltrated with local anesthetic (1\% lignocaine) using a $24 \mathrm{G} 11 \frac{1}{2}$ inch needle. A $22 \mathrm{G}$ needle of $3 \frac{1}{2}$ inch length was advanced perpendicular to the base of the skull through the coronoid notch. At about the $1 \frac{1}{2}$ to 2 inch depth, the lateral pterygoid plate was encountered. After negative aspiration of blood and cerebrospinal fluid (CSF), injection of the material was performed according to group assignment.

Group 1 was called the control group and received a block of $3 \mathrm{~mL}$ of lidocaine $0.5 \%$ plus $40 \mathrm{mg}$ of methylprednisolone and another syringe contained $1 \mathrm{~mL}$ of $0.9 \%$ saline.

Group 2 was called the calcitonin group and received a block of $3 \mathrm{~mL}$ of lidocaine $0.5 \%$ plus $40 \mathrm{mg}$ of methylprednisolone and another syringe contained 50 international units of calcitonin.

Each patient received oral $100 \mathrm{mg} / \mathrm{d}$ of diclofenac for 3 days after the procedure to minimize soreness of the needle puncture.

After the procedure, all patients received the same anticonvulsant in the same dose used before the injection. Their pain score was evaluated at each visit. Once a patient reported mild pain (VAS $\leq 3$ ), a trial for reducing anticonvulsant doses was done by reducing the dose of pregabalin by $75 \mathrm{mg}$ and that of carbamazepine by 100 mg every week, provided that the pain score was still $\leq 3$ with each reduction. If the VAS value increased to more than 3 , the patient was returned to the last controllable pregabalin or carbamazepine dose and the result was recorded in the patient's diary. Telephone consultations were allowed if there was any increase in pain that occurred during follow-up.

If pain intensity (VAS) increased to more than 3 in spite of usual dose of anticonvulsant, the pain physician started escalation of the dose until the patients received the same dose of oral anti-neuropathic therapy used before for one month. When persistent pain was reported (VAS > $3 \mathrm{~mm}$ ), the same above mentioned technique and drugs for each group was repeated and patients were re-evaluated for the efficacy and duration of the second block.

A pain physician blinded to the assignment groups was responsible for follow-up of the patients and medical management prescribing according to the predetermined protocol.

\section{Evaluation Parameters}

Pain was evaluated by VAS 0 - 10 (where 0 means no pain and 10 means the worst possible pain), before the block (basal), at 2 weeks and one month after the procedure, and monthly for one year.

Duration of the first block effective pain relief (VAS $\leq 3)$ was reported.

Repeated blockade was allowed for any patient reporting VAS > $30 \mathrm{~mm}$ in both groups during the one year follow-up period and the number of blocks were reported.

Adverse effects were also reported.

Doses of pregabalin or carbamazepine were collected at each assessment time and divided by the number of days of the period to determine daily requirements.

\section{Statistical Analysis}

Statistical analysis was carried out using SPSS version 16 (SPSS Inc., Chicago, IL). Data are presented as mean (+/-) standard deviation for quantitative data and in frequency and proportion for qualitative data. Student's t test was used for statistical analysis of quantitative data. For qualitative data, chi-squared test was used. The $P$ value was considered significant if $\leq 0.05$.

\section{Results}

Sixty-three adult patients were recruited to be involved in this randomized blind clinical trial.

History, clinical examination, and White and Sweet criteria confirmed the diagnosis of trigeminal neuralgia in 49/63 patients. Fourteen patients had atypical facial pain and were excluded from the study.

Sixteen patients responded to the oral anti-neuropathic therapy and were excluded from the study. Intractable trigeminal neuralgia that did not respond to medical therapy was reported by $33 / 49$.

Thirty-three adult patients aged between $20-60$ years old were randomly assigned into 2 groups. The demographic data, the affected side, duration of preprocedure pain in months, predisposing factors, nerve affected, and pre-procedure medications were comparable in both groups as shown in Table 1.

A significantly longer duration of effective pain relief (VAS $\leq 3$ ) was noticed in group 2 (34.7 \pm 14.2 weeks ) compared with group 1 (16.2 \pm 12.7 weeks), $P$ $<0.0004$, after the first block. The duration of effective pain relief of the second block in group 1 was $28.5 \pm$ 8.9 weeks.

Carbamazepine requirements significantly de- 
Pain Physician: September/October 2016: 19:457-464

Table 1. Patients' demographic data, predisposing factors, affected nerve, and duration of pre-procedure pain in both groups.

\begin{tabular}{|l|c|c|c||}
\hline & $\begin{array}{c}\text { Group I } \\
\text { N = 16 }\end{array}$ & $\begin{array}{c}\text { Group II } \\
\text { N = 17 }\end{array}$ & P values \\
\hline Age (Years) & $42.1 \pm 15.2$ & $49.6 \pm 18.4$ & 0.2 \\
\hline Male / Female & $5 / 11$ & $7 / 10$ & 0.6 \\
\hline Side right/left & $10 / 6$ & $12 / 5$ & 0.62 \\
\hline Predisposing factor & & & \\
Tooth extraction & 5 & 4 & 0.8 \\
Exposure to air drafts & 3 & 3 & \\
Postherpetic neuralgia & 2 & 5 & 0.2 \\
Unknown & 6 & 3 & 7 \\
\hline Nerve involved & 4 & 7 & 0.22 \\
Maxillary & 10 & $7.8 \pm 1.4$ & \\
Mandibular & $8.5 \pm 1.8$ & & \\
Mixed & \multicolumn{2}{|c||}{} \\
\hline Duration of pre-procedure pain (months) & & & \\
\hline
\end{tabular}

creased in group 2 versus group 1 at the second, third, sixth, and eighth assessment times. Meanwhile, pregabalin requirements significantly decreased in the same group at the third, fifth, sixth, and seventh assessment times. The values were comparable through other assessments as shown in Table 2.

Significantly fewer patients used anticonvulsants in group 2 at the second, third, fourth, eighth, ninth, tenth, and eleventh assessment times. Seven patients succeeded in stopping anti-neuropathic medication during the follow-up period in group 2, and 3 patients in group 1 succeeded in doing this, as shown in Table 3.

After the resolution of the analgesic effect of the first block in 12 patients in group 1, they used the same oral anti-neuropathic for one month but their symptoms again had not improved and a second block was applied. In group 2, 3 patients reported VAS > 3 and received an anti-neuropathic drug, and one patient reported a reduction of pain (VAS $<3$ ), while 2 patients had no response after one month and a second block was performed for them. Meanwhile, no one needed 3 blocks in group 2. Six patients in group 1 needed 3 blocks, as shown in Table 4.

No serious adverse events were reported during or after the interventional procedures. Seven patients had some hematomas at the site of the puncture and 6 patients in group 1 and 4 patients in group 2 had some degree of numbness and paresthesia on the side of the face which improved within 2 weeks.

VAS during the follow-up period was comparable in both groups $(P>0.05)$ (Fig. 1).

\section{Discussion}

There is great interest in the study of alternatives for management of trigeminal neuralgia because $25 \%$ of patients who present with trigeminal neuralgia require interventional procedures because of pharmacological refractoriness or intolerance (14). There is a huge variety of options, such as injection of local anesthetic, steroids or glycerol injection, radiofrequency ablation, Gamma-knife radiation, and balloon decompression of the Gasserian ganglion $(7,8)$. The classic approach to reach the Gasserian ganglion through the foramen ovale requires clinical experience and equipment which may not be widely available. Blockade of the distal branches of the trigeminal nerve (maxillary and mandibular) in the pterygopalatine or infratemporal fossa are traditionally performed using a paresthesia technique $(8,9)$ and an image-guided approach using either fluoroscopy or computed tomography, which are less readily available and more costly, especially in a developing country.

In the present study stoppage of the needle after hitting the lateral pterygoid plate is a safer and easier method for maxillary and mandibular nerve block for patients with trigeminal neuralgia involving the mandibular and maxillary branches. There were no major complications from the procedures apart from transient facial swelling which spontaneously resolved.

Both protocols were effective in alleviating pain to variable degrees. All patients had good relief of pain in comparison to pre-enrollment values. Six patients who received the steroid needed 2 blocks and 6 patients 
Calcitonin in Trigeminal Neuralgia

Table 2. Carbamezpaine and pregabalin requirements during the follow-up period. Data are presented as mean $\pm S D$ daily requirement as gm/day.

\begin{tabular}{|c|c|c|c|c|c|c||}
\hline \multirow{2}{*}{ P2 } & \multirow{2}{*}{ P1 } & \multicolumn{2}{|c|}{$\begin{array}{c}c \\
\text { Group II }\end{array}$} & \multicolumn{2}{c||}{ N = 16 } \\
\cline { 3 - 7 } & & pregabalin & carbamazepine & pregabalin & carbamazepine & \\
\hline 0.7 & 0.19 & $212.4 \pm 94.5$ & $312.5 \pm 73.3$ & $237.4 \pm 82.7$ & $350.3 \pm 52.4$ & 2 weeks \\
\hline 0.08 & 0.06 & $72.4 \pm 48.4$ & $100.2 \pm 55.4$ & $182.3 \pm 78.8$ & $164.8 \pm 65.6$ & 1 st month \\
\hline 0.38 & $0.0001^{*}$ & $67.5 \pm 32.3$ & $73.6 \pm 32.6$ & $107.4 \pm 52.4$ & $275.7 \pm 62.2$ & 2 nd month \\
\hline $0.02^{*}$ & $0.003^{*}$ & $82.6 \pm 44.1$ & $89.5 \pm 43.5$ & $197.7 \pm 42.6$ & $290.6 \pm 92.4$ & 3 rd month \\
\hline 0.08 & 0.3 & $82.6 \pm 44.1$ & $251.5 \pm 72.7$ & $186.4 \pm 64.7$ & $310.5 \pm 112.4$ & 4 th month \\
\hline $0.02^{*}$ & 0.2 & $82.6 \pm 44.1$ & $192.6 \pm 75.4$ & $202.3 \pm 42.8$ & $264.3 \pm 94.3$ & 5 th month \\
\hline $0.016^{*}$ & $0.04^{*}$ & $67.3 \pm 28.2$ & $114.8 \pm 45.6$ & $227.6 \pm 58.7$ & $375.9 \pm 162.4$ & 6 th month \\
\hline $0.018^{*}$ & 0.07 & $78.5 \pm 22.5$ & $154.8 \pm 64.3$ & $178.4 \pm 32.4$ & $390.4 \pm 182.3$ & 7 th month \\
\hline 0.14 & $0.04^{*}$ & $112.5 \pm 62.6$ & $98.7 \pm 56.3$ & $197.5 \pm 72.2$ & $320.4 \pm 152.5$ & 8 th month \\
\hline 0.11 & 0.5 & $92.5 \pm 22.6$ & $218.7 \pm 116.4$ & $152.3 \pm 52.8$ & $294.5 \pm 175.8$ & 9 th month \\
\hline 0.34 & 0.5 & $82.6 \pm 44.1$ & $294.4 \pm 53.21$ & $147.4 \pm 82.6$ & $385.4 \pm 262.2$ & 10 th month \\
\hline 0.4 & 0.11 & $82.6 \pm 44.1$ & $98.7 \pm 56.3$ & $167.4 \pm 117.7$ & $277.4 \pm 163.4$ & 11 th month \\
\hline 0.3 & 0.12 & $82.6 \pm 44.1$ & $98.7 \pm 56.3$ & $177.4 \pm 93.1$ & $344.4 \pm 232.5$ & 12 th month \\
\hline
\end{tabular}

*Significant difference between both groups

P1 comparison between carbamezpaine requirements in both groups

P2 comparison between pregabalin requirements in both groups

Table 3. Number of patients who used carbamazepine or pregabalin during the follow-up period. Data are presented as a number.

\begin{tabular}{|c|c|c|c|c|c|}
\hline \multirow[t]{2}{*}{$\boldsymbol{P}$} & \multicolumn{2}{|c|}{$\begin{array}{c}\text { Group II } \\
\mathbf{N}=17\end{array}$} & \multicolumn{2}{|c|}{$\begin{array}{c}\text { Group I } \\
\mathbf{N}=16\end{array}$} & \multirow[t]{2}{*}{ Time } \\
\hline & pregabalin & carbamazepine & pregabalin & carbamazepine & \\
\hline 1 & 5 & 12 & $\overline{6}$ & 10 & 2 weeks \\
\hline 0.16 & 3 & 7 & 5 & 8 & 1st month \\
\hline $0.02^{*}$ & 2 & 5 & 5 & 8 & 2nd month \\
\hline $0.02^{*}$ & 2 & 4 & 5 & 7 & 3rd month \\
\hline $0.02^{*}$ & 2 & 5 & 6 & 7 & 4th month \\
\hline 0.38 & 2 & 5 & 5 & 4 & 5th month \\
\hline 0.056 & 2 & 3 & 5 & 5 & 6th month \\
\hline 0.056 & 2 & 3 & 4 & 6 & 7th month \\
\hline $0.007^{*}$ & 3 & 3 & 5 & 8 & 8th month \\
\hline $0.049^{*}$ & 3 & 4 & 6 & 6 & 9th month \\
\hline $0.008^{*}$ & 2 & 4 & 6 & 7 & 10th month \\
\hline $0.002^{*}$ & 2 & 3 & 4 & 7 & 11th month \\
\hline 0.12 & 2 & 3 & 3 & 6 & 12th month \\
\hline
\end{tabular}

${ }^{*}$ Significant difference between both groups 
needed 3 blocks. Only 2 patients needed 2 blocks in the calcitonin group.

Although VAS was comparable between groups during the follow-up period, the benefit of calcitonin over steroid was reflected by the diminishing the need for repeated injection, decreasing carbamazepine and pregabalin requirements by 4 and 3 times, respectively, from the assessment values. A significantly smaller number of patients used anticonvulsants in the calcitonin group. Moreover, 7 patients succeeded in stopping anti-neuropathic medication during the follow-up period in the same group, versus 3 patients in the steroid group.

Steroids accelerate the healing process of an irritated nerve, reduce edema, and inhibit the inflammatory cascade (8). Some authors have questioned the significance of other materials such as streptomycin,

Table 4. Number of needed blocks in each group.

\begin{tabular}{|l|c|c|c||}
\hline & $\begin{array}{c}\text { Group I } \\
\text { N = 16 }\end{array}$ & $\begin{array}{c}\text { Group II } \\
\text { N = 17 }\end{array}$ & \multirow{2}{*}{ P values } \\
\hline One block & 4 & 15 & \multirow{2}{*}{$0.0007^{\star}$} \\
\cline { 1 - 3 } Two blocks & 6 & 2 & \\
\hline Three blocks & 6 & - & \\
\hline
\end{tabular}

*Significant difference between both groups lidocaine (15-17), alcohol (18), and botulinum toxin (19). However, most of these therapies have not been effective and one-year recurrence is greater than $50 \%$.

Ito et al (20) and Takayama et al (21) postulated that the descending serotonergic system is involved in the analgesic effect of calcitonin in post-menopausal states by modifying the expression of serotonin receptors at the central terminals of $C$ afferents. Meanwhile, another study (12) revealed the presence of a calcitonin receptor-mediated system which might regulate the excitability of primary afferents by activation of calcitonin-induced signals via the calcitonin receptors to control the sodium channel in the dorsal root ganglia neurons. Moreover, this system is silent under normal conditions but becomes active following nerve injury. The role of a calcitonin receptor-mediated system in the peripheral nerve tissue may be a promising tool for management of neuropathic pain.

Calcitonin has been reported to relieve neuropathic pain associated with lumbar spinal canal stenosis (22), diabetic neuropathy (23), complex regional pain syndrome I (24), and postherpetic neuralgia (25).

A potential weakness of our study was that it did not include patients with combined therapy of antineuropathic medications or patients who used other adjuvants like baclofen or clonazepam. So, we included

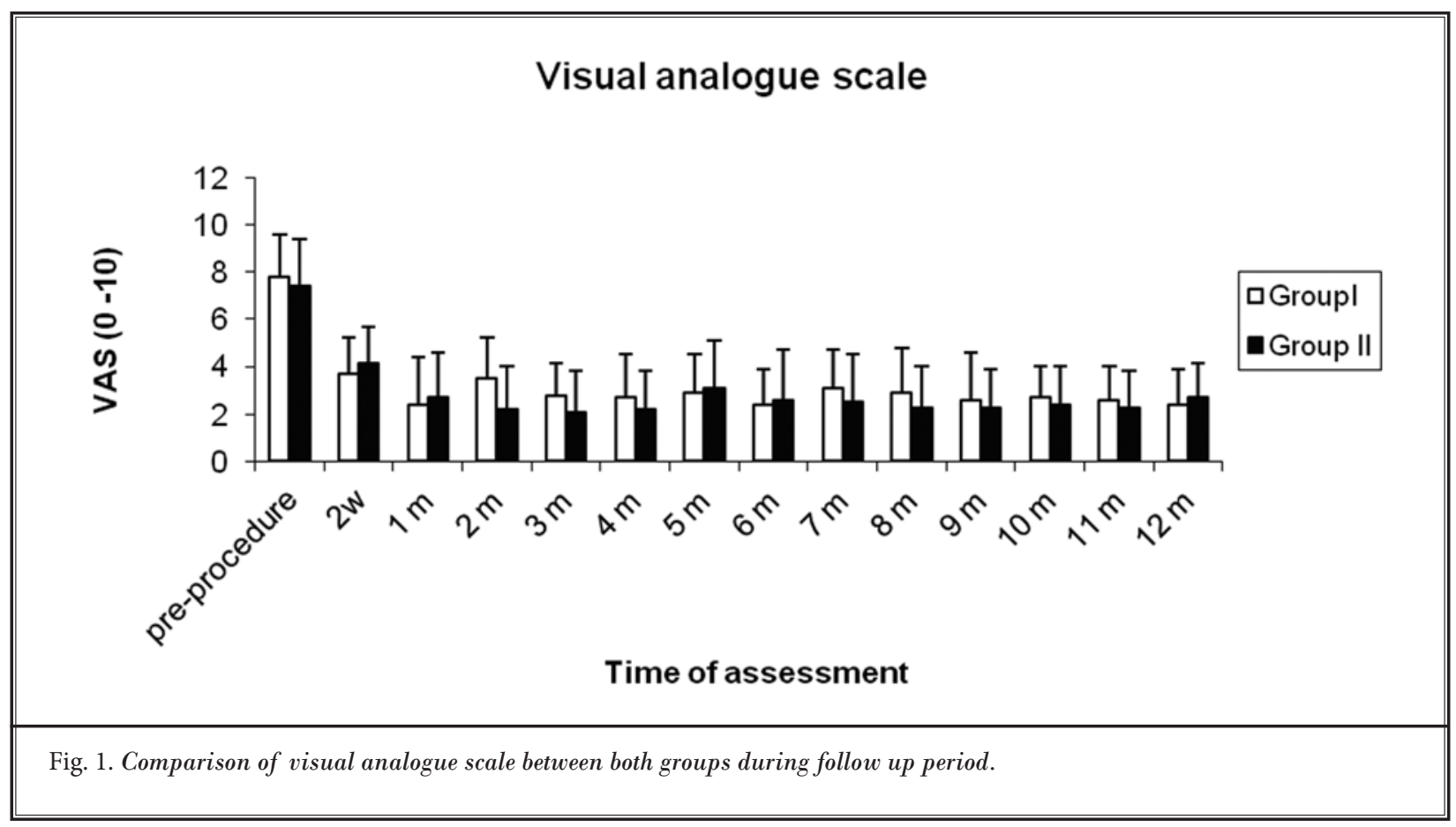


a special category of patients, because the scope of the current study was testing the validity of calcitonin in trigeminal neuralgia.

\section{Conclusion}

Although limited by a low number of patients, the present study suggests that calcitonin may be a useful additive to local anesthetic and steroid in the management of trigeminal neuralgia. Also, a modified coronoid approach to the maxillary and mandibular nerve is simple, free of radiation, safe, and may be an effective percutaneous procedure for treating trigeminal neuralgia.

Chart 1. Flow diagram of patient progress through the phases of the randomized trial.
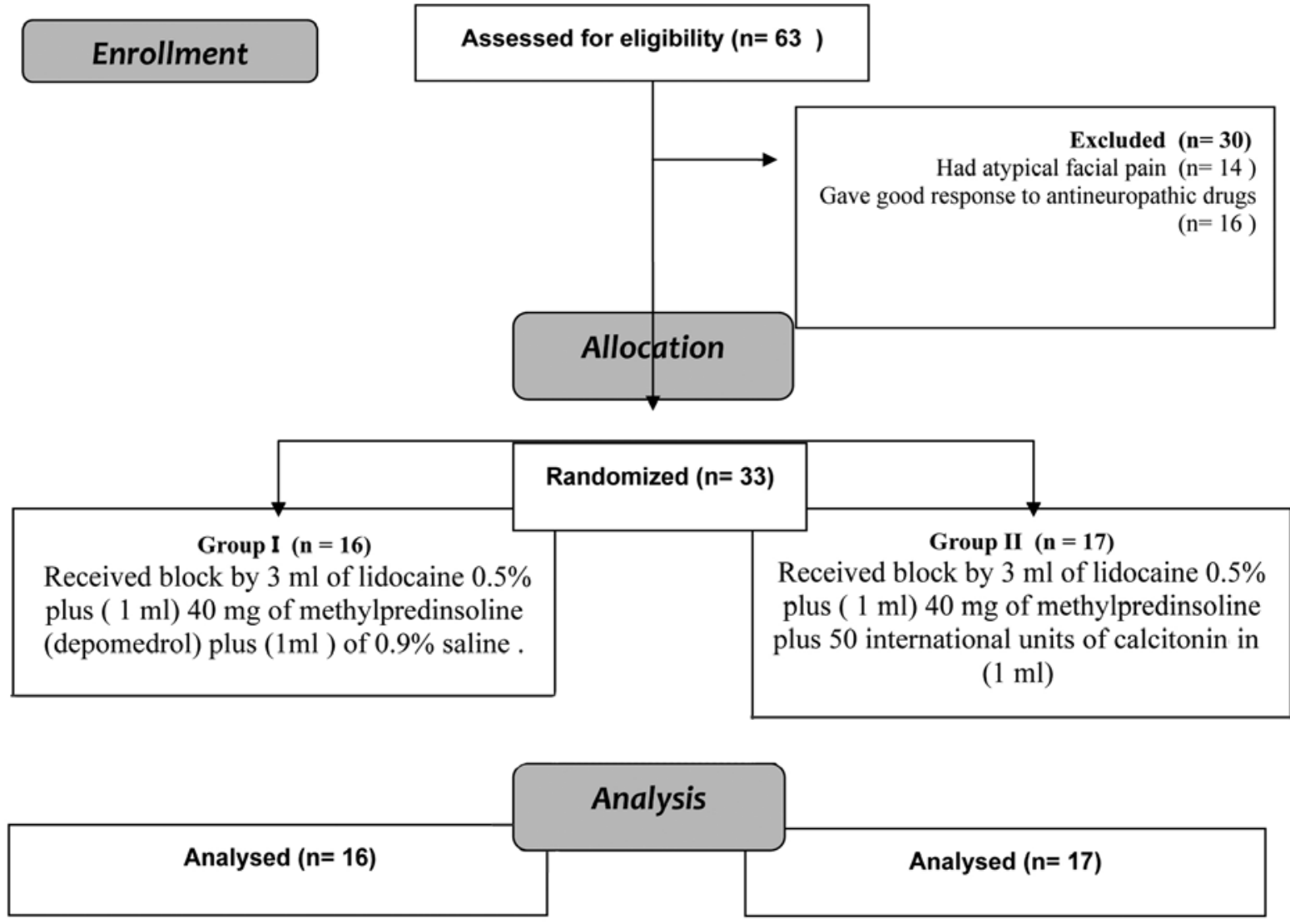


\section{References}

1. Nurmikko TJ, Eldridge PR. Trigeminal neuralgia-pathophysiology, diagnosis and current treatment. $\mathrm{Br}$ J Anaesth 2001; 87:117-132.

2. Wang QP, Bai M. Topiramate versus carbamazepine for the treatment of classical trigeminal neuralgia: A meta-analysis. CNS Drugs 2011; 25:847-857.

3. Gomez-Arguelles JM , Dorado R, Sepulveda JM, Herrera A, Arrojo FG, Aragon E, Huete CR, Terron C, Anciones B. Oxcarbazepine monotherapy in carbamazepine-unresponsive trigeminal neuralgia. J Clin Neurosci 2008; 15:516-519.

4. Jorns TP, Zakrzewska JM. Evidencebased approach to the medical management of trigeminal neuralgia. $\mathrm{Br}$ J Neurosurg 2007; 21:253-261

5. Canavero S, Bonicalzi V. Drug therapy of trigeminal neuralgia. Expert Rev Neurother 2006; 6:429-440.

6. Lenchig S, Cohen J, Patin D. A minimally invasive surgical technique for the treatment of posttraumatic trigeminal neuropathic pain with peripheral nerve stimulation. Pain Physician 2012; 15:E725-E732.

7. Henson CF, Goldman HW, Rosenwasser $\mathrm{RH}$, Downes MB, Bednarz G, Pequignot EC, Werner-Wasik M, Curran WJ, Andrews DW. Glycerol rhizotomy versus gamma knife radiosurgery for the treatment of trigeminal neuralgia: An analysis of patients treated at one institution. J Radiat Oncol Biol Phys 2005; 1: 82-90.

8. Vasudha jadhav V, Diwanmal BM, Jadhav R. Clinical experience in maxillary and mandibular division block for trigeminal neuralgia: A review of its use in trigeminal neuralgia. IOSR Journal of Pharmacy 2015; 5:37-39.

9. Konishi R, Mitsuhata H, Akazawa, S,
Shimizu R. Temporary severe vertigo associated with mandibular nerve block with absolute alcohol for treatment of trigeminal neuralgia. Anesthesiology 1997; 87:699-700.

10. Mahoney PM. Maxillary nerve block. Anesth Prog 1977; 24:47-49.

11. Waldman SD. Trigeminal nerve block by the coronoid approach. A prospective study of complications during 580 consecutive nerve blocks. Pain Clinic 1994; 3:211-214.

12. Ito A, Takeda M, Yoshimura Y, Komatsu T, Ohno T, Kuriyama H, Matsuda A, Yoshimura M. Anti-hyperalgesic effects of calcitonin on neuropathic pain interacting with its peripheral receptors. Molecular Pain 2012; 8:42.

13. White JC, Sweet WH. Pain and Neurosurgeon. Charles C. Thomas, Springfield, IL, 1969.

14. Bovim G, Sand T. Cervicogenic headache, migraine without aura and tension-type headache. Diagnostic blockade of greater occipital and supra-orbital nerves. Pain 1992; 51:43-48.

15. Stajci 'c Z, Juniper RP, Todorovi'c L. Peripheral streptomycin / lidocaine injections versus lidocaine alone in the treatment of idiopathic trigeminal neuralgia. A double blind controlled trial. ] Cranio maxillo Fac Surg 1990; 18:243-246.

16. Bittar GT, Graff SB. The effects of streptomycin / lidocaine block on trigeminal neuralgia: A double blind cross over placebo controlled study. Headache 1993; 33:155-60.

17. Han K, Kim C, Chae Y, Kim D. Efficacy and safety of high concentration lidocaine for trigeminal nerve block in patients with trigeminal neuralgia. Int ] Clin
Pract 2008; 62:248-254.

18. Oturai $A B$, Jensen $K$, Eriksen J, Madsen $F$. Neurosurgery for trigeminal neuralgia: Comparison of alcohol block, neurectomy, and radiofrequency coagulation. Clin ] Pain 1996; 12:311-315.

19. Allam N, Brasil-Neto JP, Brown G, Tomaz C. Injections of botulinum toxin type a produce pain alleviation in intractable trigeminal neuralgia. Clin J Pain 2005; 21:182-184

20. Ito A, Kumamoto E, Takeda M, Shibata $\mathrm{K}$, Sagai H, Yoshimura M. Mechanisms for ovariectomy-induced hyperalgesia and its relief by calcitonin: Participation of 5 - $\mathrm{HT} 1 \mathrm{~A}$-like receptor on $\mathrm{C}$-afferent terminals in substantia gelatinosa of the rat spinal cord. J Neurosci 2000; 20:6302-6308.

21. Takayama B, Kikuchi S, Konno S, Sekiguchi M. An immunohistochemical study of the antinociceptive effect of calcitonin in ovariectomized rats. BMC Musculoskelet Disord 2008; 15:164.

22. de Tran QH, Duong S, Finlayson RJ. Lumbar spinal stenosis: A brief review of the nonsurgical management. Can J Anaesth 2010; 57:694-703.

23. Quatraro A, Minei A, De Rosa N, Giugliano D. Calcitonin in painful diabetic neuropathy. Lancet 1992; 339:746-747.

24. Perez RS, Kwakkel G, Zuurmond WW, de Lange JJ. Treatment of reflex sympathetic dystrophy (CRPS type 1): A research synthesis of 21 randomized clinical trials. J Pain Symptom Manage 2001; 21:511-526.

25. Visser EJ, Kwei PL. Salmon calcitonin in the treatment of post herpetic neuralgia. Anaesth Intensive Care 2006, 34:668-671. 